\title{
Optimizing the Aesthetic Result and Safety of Inferior Pedicle Reduction Mammaplasty
}

\author{
HOSSAM Y. ELKAFRAWY, M.D.; AHMED A. ZIDAN, M.D. and ADHAM FAROUK, M.D. \\ The Department of General Surgery, Plastic Surgery Unit, Faculty of Medicine, Alexandria University, Egypt
}

\begin{abstract}
Background: The inferior pedicle Wise pattern breast reduction is one of the most popular techniques used. However, some criticism and disadvantages of the technique needs to be revised and modified to reach better results.

Patients and Methods: This is a prospective randomized study that included 30 female patients suffering from breast hypertrophy and they are candidate for the proposed technique. They under go breast reduction procedure with modified inverted T/inferior pedicle technique.

Results: This study includes 30 female patients of an age ranged between 24-53 years old and a breast size (suprasternal notch to nipple distance) ranging from 30 to $43 \mathrm{~cm}$. The weight of removed tissues during surgery in our study was ranging from 650 to 1980 grams. The follow-up for 1-year postoperative shows patient satisfaction reaching $70 \%$.

Conclusion: Modification and refining the inverted T/inferior pedicle technique could give us a better aesthetic and functional results with minimization of the problems associated with this technique.
\end{abstract}

Key Words: Inferior pedicle reduction - Mammaplasty.

\section{INTRODUCTION}

The breast reduction procedure is a greater opportunity for the surgeon to demonstrate his or her aesthetic and reconstructive abilities. In such cases, there is an excess of skin, fat and parenchyma which is coupled with an overall breast shape that is usually less than aesthetic [1,2]. With careful surgical manipulation of the volume of the breast along with intelligent incision planning, a beautiful and long-lasting breast shape can be created that complements the reduction in breast volume. The ideal breast reduction surgery would transform large, uncomfortable, unattractive breasts to smaller, comfortable, attractive breasts without sacrificing, and perhaps even enhancing, sensuality, sexuality, and function [3-7].

Breast reduction using an inverted $\mathrm{T}$ scar skin design with inferior pedicle is widely practiced and is the standard by which more recent limited scar techniques are judged [8,9]. The inverted $\mathrm{T}$ procedures are attractive because they are predictable and versatile and permit great control over both the extent of reduction and the breast-shaping process [10]. Despite these advantages, common criticisms of inverted $\mathrm{T}$ scar techniques include breast shape abnormalities, areolar malposition, hypertrophic scars, and poor long-term projection $[11,12]$.

Through modification in inverted $\mathrm{T}$ scar/inferior pedicle technique some of these disadvantages could be minimized. In this study changes in preoperative marking, thinning of the lateral flaps, together with widening modification of the base of the inferior pedicle flap, could optimize the aesthetic results together with improving safety of the procedure.

\section{PATIENTS AND METHODS}

This study will be conducted on patients suffering from breast enlargement during the period between January 2013 to September 2016 at the Department of Plastic and Reconstructive Surgery at Alexandria main University Hospital.

\section{Markings:}

The markings were performed with the patient in the standing position. The breast meridian was determined as a vertical line which was drawn from the mid-clavicle to the inframammary fold, separating the breast mass equally. This line was generally toward the nipple-areola complex, unless the complex was severely displaced, which was usually medial displaced.

The inframammary fold was then marked, extending medially from a point at last $3 \mathrm{~cm}$ from the midline of the chest and extending medial to the anterior-axillary line by $2-3 \mathrm{~cm}$. The level of the inframammary fold was placed about $1-2 \mathrm{~cm}$ below its original level taking in consideration its new level postoperative to prevent upward migration. 
Markings for nipple placement were made along the breast meridian at a level that accounts for the patient's beast size and shape, height, and degree of nipple ptosis. Nipple placement was generally located between 21 and $26 \mathrm{~cm}$ from the sternal notch, guided by the projection of the level of the inframammary fold. The Wise pattern was marked guided by the adjustable McKissock [8] keyhole breast marker. The pattern was traced using $5-6 \mathrm{~cm}$ vertical limbs and a $42 \mathrm{~mm}$ areolar diameter.

A pinch test was performed between the vertical limbs to ensure that the planned skin resection was not overly aggressive. Symmetry of the markings should be checked by measuring the suprasternal notch-to-new nipple distance, as well as the inframammary fold-to-nipple distance, bilaterally.

\section{Operative technique:}

With the patient in the supine position, the patient was widely prepped and draped. A 38$42 \mathrm{~mm}$ areola marker was used to mark the new areola circumference on unstretched breast skin. An inverted-U was marked around the new areola and centered on the breast meridian, extending inferiorly to the inframammary fold and delineating the inferior pedicle.

The skin of the pedicle was deepithelialized then the medial, lateral, and superior borders of the pedicle are incised down with a slop preserving the fibrous attachment of the breast flap with its containing blood and nervous supply specially the breast horizontal septum takes its origin from the periosteum of the fifth rib [13-15] converting the flap to assort of central flap without excess parenchymal tissue (Fig. 1).

The adipocutaneous flap was elevated off the chest wall superiorly up to the level of the clavicles, medially to the sternum, and laterally up to the border of the latissimus dorsi muscle. The inframammary fold was then incised medially and laterally from the base of the pedicle. More excision take place on the lateral side up to the axillary tail with thinning of the lateral part of adipocutaneous flap with flap thickness of $2 \mathrm{~cm}$ at the start reaching $4 \mathrm{~cm}$ after (Fig. 2) and preservation of tissues on the medial side aiming for creating more medial fullness.

Closure was initiated by placing a triangular stitch in the corners of the flaps to the midpoint of the inframammary line. Drains were placed, exiting in the mid-axillary line bilaterally. Interrupted, buried sub-dermal sutures were placed along the inframammary incision. The vertical limb is closed over the pedicle in similar fashion.
If excess skin was encountered at the lateral end of the inframammary the wound was closed in a fish-mouth fashion in order to avoid increasing the wound length and preventing scars in the axillary region which could complicate by hypertrophic scars (Fig. 3).

After that the well-vascularized nipple-areola complex was tacked in place using interrupted, buried dermal sutures. A running subcuticular stitch was placed along the entire incision. All sutures used were absorbable, with the exception of the drain stitch.

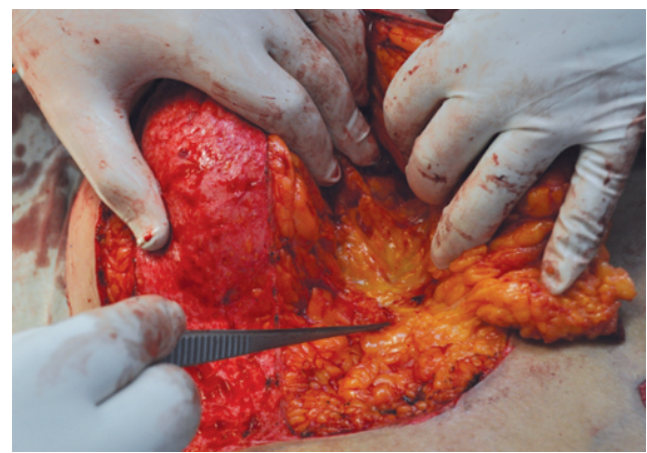

Fig. (1): After dissection of the inferior flap showing the preserved breast horizontal septum.

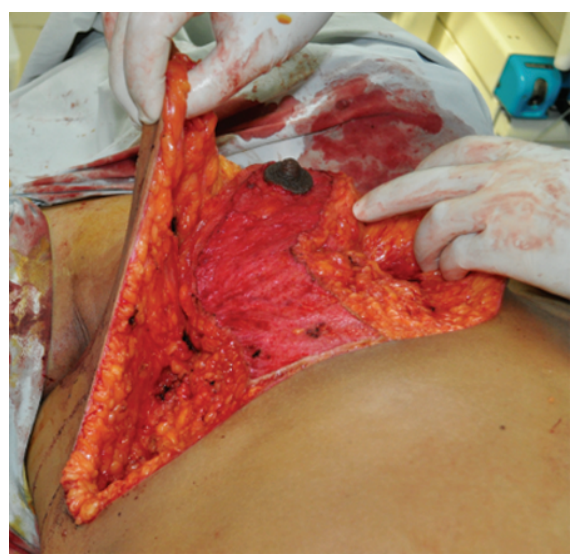

Fig. (2): Sowing the remining breast tissue after medial and lateral excision and the thinning of the lateral skin flap.

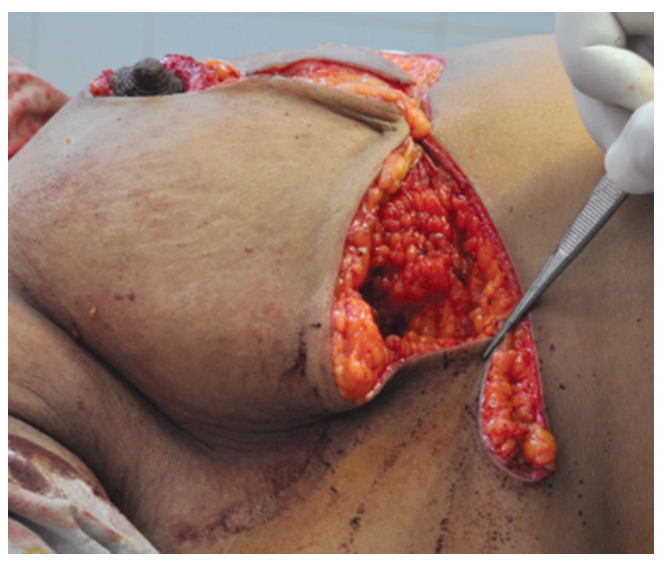

Fig. (3): The fish-mouth method of closure the lateral end of the inframammary incision. 

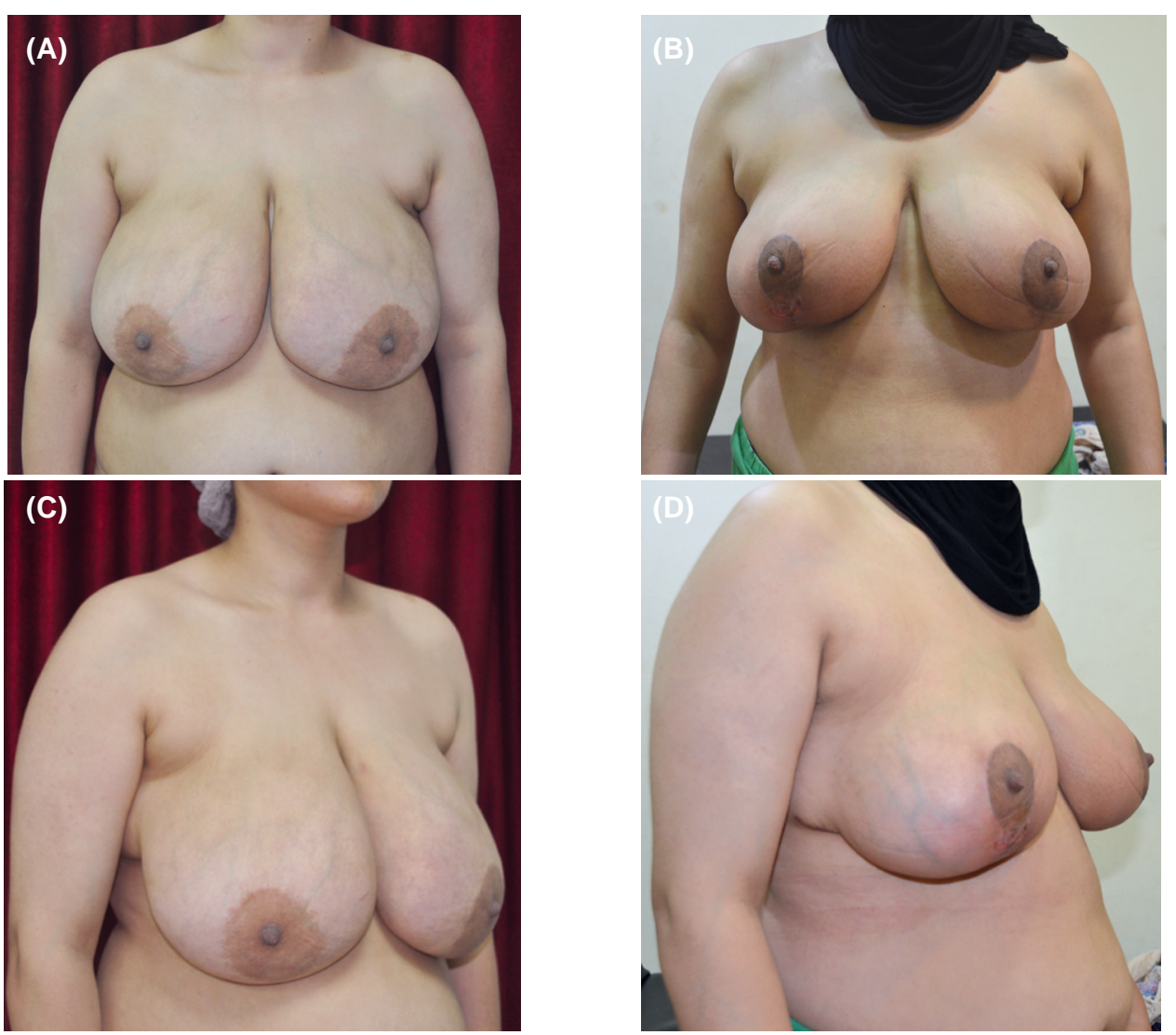

Fig. (4): 38-years old patient, (A,C) Preoperative anterior and lateral view, (B,D) Postoperative anterior and lateral view.
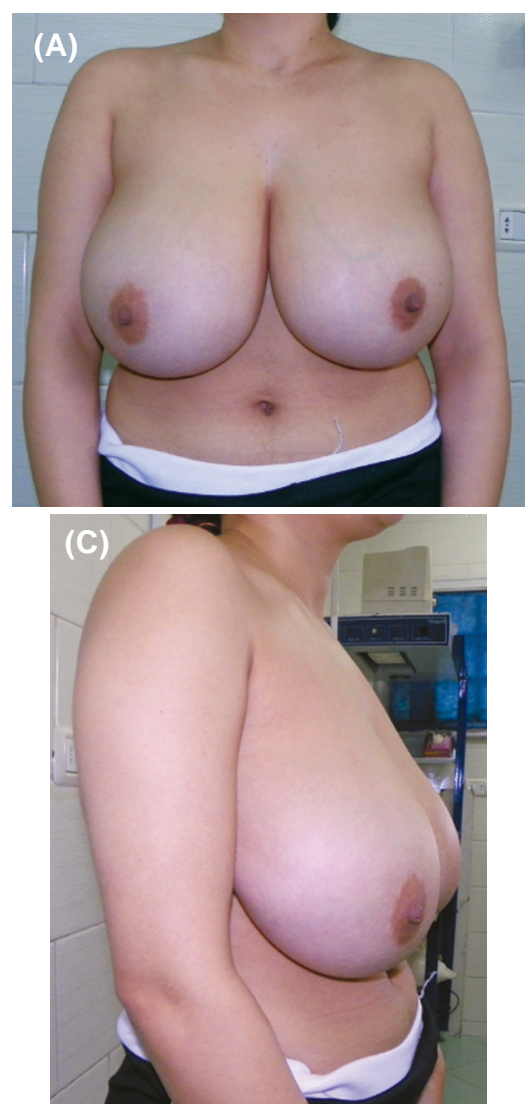
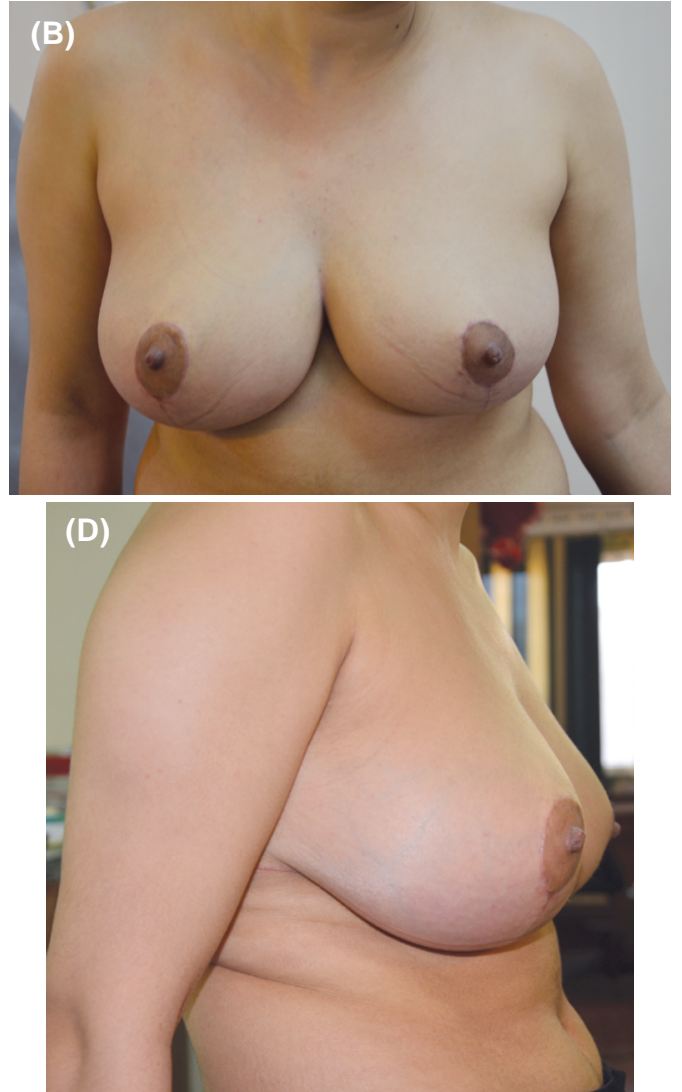

Fig. (5): 27-years old patient, (A,C) Preoperative anterior and lateral view, (B,D) Postoperative anterior and lateral view. 


\section{RESULTS}

The present study was conducted on 30 female patients with Breast Hypertrophy admitted to Plastic Surgery Unit at Alexandria Main University Hospital.

The study included 30 females. Their ages ranged from 24 years old to 53 years old. The mean age was 33.35 years. The mean BMI of the studied patients was $30.10 \pm 1.64$; ranging from 29 to 32 and the median BMI was 30.8 .

The breast size in our study was ranging from 30 to $42 \mathrm{~cm}$ with a mean of $(35.40 \pm 3.64) \mathrm{cm}$ in the right side and from 31 to $43 \mathrm{cms}$ with a mean $(36.20 \pm 3.39) \mathrm{cm}$ in the left side (Table 1).

The weight of removed tissues during surgery in our study was ranging from 650 to 1980 grams with a mean of $967.0 \pm 332.3$ grams and median was 953 grams in the right side and from 695 to 1860 grams with a mean of $954.5 \pm 327.4$ grams and median was 945 grams in the left side (Table 2).

The preoperative areola fold distance in our study was ranging from $12-18 \mathrm{~cm}$ with a mean of $15.45 \pm 1.51 \mathrm{~cm}$ and median was $15.35 \mathrm{~cm}$ in the right side and from 13 to $18 \mathrm{~cm}$ with a mean of $15.45 \pm 1.36 \mathrm{~cm}$ and median was $15.25 \mathrm{~cm}$ in the left side.

The immediate postoperative areola fold distance in our study was ranging from $5-7 \mathrm{~cm}$ with a mean of $6.03 \pm 0.60 \mathrm{~cm}$ and median was $6 \mathrm{~cm}$ in the right side and from 5 to $7.5 \mathrm{~cm}$ with a mean of $6.13 \pm 0.70 \mathrm{~cm}$ and median was $6 \mathrm{~cm}$ in the left side.

The 6 months post-operative areola fold distance in our study was ranging from $5.4-7.5 \mathrm{~cm}$ with a mean of $6.44 \pm 0.39 \mathrm{~cm}$ and median was $6.55 \mathrm{~cm}$ in the right side and from $5.5-7.6 .0 \mathrm{~cm}$ with a mean of $6.37 \pm 0.53 \mathrm{~cm}$ and median was $6.60 \mathrm{~cm}$ in the left side.

The 1-year post-operative areola fold distance in our study was ranging from $6-9 \mathrm{~cm}$ with a mean of $7.42 \pm 0.72 \mathrm{~cm}$ and median was $7.2 \mathrm{~cm}$ in the right side and from $6-9 \mathrm{~cm}$ with a mean of $7.63 \pm 1.05 \mathrm{~cm}$ and median was $7.3 \mathrm{~cm}$ in the left side (Table 3 ).

In our study Hematoma occurred in one case $(3 \%)$ in the left breast, Seroma occurred in one case $(5 \%)$ in the left breast, wound healing problems in 3 cases (9\%) at the T-junction, and partial nipple loss in 3 cases (9\%) 1 case with bilateral partial loss and 2 cases with unilateral partial loss (Table 4).
We found that $70 \%$ of patients were satisfied, $20 \%$ of patients were somewhat satisfied/somewhat dissatisfied and $10 \%$ of patients were dissatisfied (Table 5).

Table (1): Descriptive analysis of the studied cases according to notch to NAC distance $(\mathrm{CM})(\mathrm{n}=20)$.

\begin{tabular}{lll}
\hline $\begin{array}{l}\text { Notch to NAC } \\
\text { distance }(\mathrm{cm})\end{array}$ & Right & \multicolumn{1}{c}{ Left } \\
\hline Min. - Max. & $30.0-42.0$ & $31.0-43.0$ \\
Mean \pm SD & $35.40 \pm 3.64$ & $36.20 \pm 3.39$ \\
Median & 36.60 & 36.50 \\
\hline
\end{tabular}

Table (2): Descriptive analysis of the studied cases according to removed tissue $(n=20)$.

\begin{tabular}{lll}
\hline Removed tissue $(\mathrm{g})$ & \multicolumn{1}{c}{ Right } & \multicolumn{1}{c}{ Left } \\
\hline Min. - Max. & $65.0-1980.0$ & $695.0-1860.0$ \\
Mean \pm SD & $967.0 \pm 332.3$ & $954.5 \pm 327.4$ \\
Median & 953.0 & 945.0 \\
\hline
\end{tabular}

Table (3): Descriptive analysis of the studied cases according to areola-fold distance $(n=20)$.

\begin{tabular}{lll}
\hline Areola-fold distance & \multicolumn{1}{c}{ Right } & \multicolumn{1}{c}{ Left } \\
\hline Preoperative: & & \\
$\quad$ Min. - Max. & $12.0-18.0$ & $13.0-18.0$ \\
$\quad$ Mean \pm SD & $15.45 \pm 1.51$ & $15.45 \pm 1.36$ \\
$\quad$ Median & 15.35 & 15.25 \\
Immediate postoperative: & & \\
$\quad$ Min. - Max. & $5.0-7.0$ & $5.0-7.50$ \\
Mean \pm SD & $6.03 \pm 0.60$ & $6.13 \pm 0.70$ \\
Median & 6.0 & 6.0 \\
Post-operative after 6 months: & & \\
Min. - Max. & $5.4-7.5$ & $5.5-7.6 .0$ \\
Mean \pm SD & $6.44 \pm 0.39$ & $6.37 \pm 0.53$ \\
Median & 6.55 & 6.60 \\
Post-operative after 1 year: & & \\
Min. - Max. & $6.0-9.0$ & $6.0-9.0$ \\
Mean \pm SD & $7.42 \pm 0.72$ & $7.63 \pm 1.05$ \\
Median & 7.2 & 7.3 \\
\hline
\end{tabular}

Table (4): Recorded complications of the cases $(n=20)$.

\begin{tabular}{lccccc}
\hline & \multicolumn{2}{c}{ Right } & & \multicolumn{2}{c}{ Left } \\
\cline { 2 - 3 } \cline { 6 - 7 } & No. & $\%$ & & No. & $\%$ \\
\hline Haematoma & 0 & 0.0 & & 1 & 3.0 \\
Seroma & 0 & 0.0 & & 1 & 3.0 \\
Wound healing problems & 1 & 3.0 & & 3 & 9.0 \\
Partial nipple loss & 1 & 3.0 & & 3 & 9.0 \\
\hline
\end{tabular}

Table (5): Distribution of the studied cases according to patient satisfaction $(n=20)$.

\begin{tabular}{llc}
\hline Patient satisfaction & No. & $\%$ \\
\hline Dissatisfied & 3 & 10.0 \\
Somewhat satisfied/Somewhat dissatisfied & 6 & 20.0 \\
Satisfied & 21 & 70.0 \\
\hline
\end{tabular}




\section{DISCUSSION}

All the techniques defined for breast reduction surgery aim to eliminate the physical and psychological problems of the patients and provide aesthetic breast shape that last for a long period of time. To make breast reduction surgery a more safe and reliable procedure with a high level of patient satisfaction we need to apply some changes and refinement of the original techniques.

Patterns to fit different sized breasts described by Wise [16] and simplified by the adjustable McKissock [8] keyhole breast marker still remains the most common pattern of skin incision used in large reduction mammaplasty, as it allows for flexibility in the method of nipple/areola transposition and gives a predictable result. Together with inferior pedicle, this technique presents a very common method of surgical breast reduction as for its reliability and relative easiness of execution. But still this technique has disadvantages, as regard the scar length, tendency for bottoming out, and pedicle safety in very large breast reduction [3,4], that needs some refinements and modifications to overcome these disadvantages.

The most common cause of patient dissatisfaction in breast reduction surgery is scarring $[\mathbf{1 7}, \mathbf{1 8}]$. Celebrier et al. [19] performed a retrospective review assessing patients' and surgeons' perspectives on the scar components after reduction mammaplasty using the inferior pedicle technique. They determined that patients were most satisfied with the periareolar scar and less satisfied with the inframammary scar. Reliving tension on the periareolar scar together with shorting of the inframammary scar can improve the results and solve partly the problem of long scar associated with inverted $\mathrm{T}$ technique.

Cutting around the NAC a circumference of $42 \mathrm{~mm}$ on unstretched skin was very useful to provide enough tissues in the NAC to prevent tension on the periareolar scar resulting in a very acceptable scar. The inframammary incision was shortened both medially and laterally to avoid areas that usually result in hypertrophic scaring, specially in the axillary area where fish-mouth pattern of wound closure and excision of additional adipose tissue in these regions with beveling of the fat way from the incision were very helpful in large breast reductions with axillary extension that results in "dog ear" usually end in elongated inframammary scar laterally.

In our study during the inferior flap dissection we make sure of preservation of the breast hori- zontal septum. Anatomical investigations showed that this septum is part of a suspension apparatus, which is attached to the thoracic wall, mainly following the borders of pectoralis major [20,21]. This ligamentous suspension carries the whole weight of the breast like a sling, thereby determining the shape of the breast. Preservation of this ligamentous suspension is not only important because of its shaping potential, and contribute in preventing bottoming out, its main importance lies in the fact that it is the guiding structure of the main nerves and vessels to the nipple.

The focusing on excision more tissues from the lateral breast tissue, which is usually noticeably more than the medial part in large breasts, and preservation of the medial breast tissue helped us to correct the aesthetic problems of the enlarged breast. The excessive removal of the lateral breast tissues and thinning of the lateral flap leads to correction of the lateral fullness and shapes the axillary hollow. While preservation of the medial tissues aimed to create medial fullness and accentuation of the medial cleavage.

Skin necrosis and/or wound breakdown were most likely to occur at the intersection of the vertical and transverse incisions, which is the region of maximum tension. Careful tissue handling, maintenance of flap thickness, and a lowtension closure helped to prevent devascularization from occurring. When wound breakdown did occur, in 3 cases, local wound care was usually the adequate treatment.

\section{REFERENCES}

1- Regnault P.: Breast ptosis. Definition and treatment. Clin. Plast. Surg., 3 (2): 193-201, 1976.

2- Ppitanguy I.: Surgical treatment of breast hypertrophy. Br. J. Plast. Surg., 20 (1): 78-85, 1967.

3- Shakesppeare V. and Popostle K.: A qualitative study of patients' views on the effects of breast-reduction surgery: A 2-year follow-up survey. Br. J. Plast. Surg., 52 (3): 198204, 1999.

4- Blomqvist L., Eriksson A. and Brandberg Y.: Reduction mammaplasty provides long-term improvement in health status and quality of life. Plast. Reconstr. Surg., 106 (5): 991-997, 2000.

5- Hamdi M., Greuse M., Nemec E., Deprez C. and DeMey A.: Breast sensation after superior pepdicle versus inferior pedicle mammaplasty: Anatomical and histological evaluation. Br. J. Plast. Surg., 54 (1): 43-46, 2001.

6- Marshall D.R., Callan P.P. and Nicholson W.: Breastfeeding after reduction mammaplasty. Br. J. Plast. Surg., 47 (3): 167-169, 1994.

7- Brzozowski D., Niessen M., Evans B. and Hurst L.N.: Breastfeeding after inferior pedicle reduction mammaplasty. Plast. Rec. Surg., 105 (2): 530-534, 2000. 
8- McKissock P.K.: Reduction mammaplasty with a vertical dermal flap. Plast. Reconstr. Surg., 49 (3): 245-252, 1972.

9- Robbins T.H.: A reduction mammaplasty with areolarnipple based on an inferior dermal pedicle. Plast. Reconstr. Surg., 59 (1): 64-67, 1977.

10- Nahai F.: The art of aesthetic surgery: Principles and techniques, Quality Medical Publishing, Inc., p. 1799, 2005.

11- Mugea T.T.: Rules in breast aesthetic surgery. The $4^{\text {th }}$ international congress of romainan aesthetic surgery society, Bucharest, Romania, October 3-5 th 2002.

12- Faria F.S., Guthrie E., Bradbury E. and Brian A.N.: Psychosocial outcome and patient satisfaction following breast reduction surgery. Br. J. Plast. Surg., 52 (6): 448452, 1999.

13- Nakajima H., Imanishi N. and Aiso S.: Arterial anatomy of the nipple-areola complex. Plast. Reconstr. Surg., 96 (4): 439-450, 1995.

14- Sarhadi N.S., Shaw Dunn J., Lee F.D. and Soutar D.S.: An anaatomical study of the nerve supply of the breast, including the nipple and areola. Br. J. Plast. Surg., 49 (3): 156-164, 1996

15- Wuringer E., Mader N., Posch E. and Holle J.: Nerve and vessel supplying ligamentous suspension of the mammary gland. Plast. Reconstr. Surg., 101 (6): 1486-1493, 1998.

16- Wise R.J.: A preliminary report on a method of planning the mammaplasty. Plast. Reconstr. Surg., 17: 367, 1956.

17- Godwin Y., Wood S.H. and O'Neil T.J.: A comparison of the patient and surgeon opinion on the long-term aesthetic outcome of reduction mammaplasty. Br. J. Plast. Surg., 51 (6): 444-44914, 1998.

18- Mizgala C.L. and MacKenzie K.M.: Breast reduction outcome study. Ann. Plast. Surg., 44 (2): 125-13315, 2000.

19- Celebiler O., Sonmez A., Erdim M., Yaman M. and Numanoglu A.: Patients' and surgeons' perspectives on the scar components after inferior pedicle breast reduction surgery. Plast. Reconstr. Surg., 116 (2): 459-464, 2005.

20- Würinger E. and Tschabitscher M.: New aspects of the topography of the mammary gland regarding its neurovascular supply along a regular ligamentous suspension. Eur. J. Morphol., 40 (3): 181-9, 2003.

21- Würinger E.: Vertical scar mammaplasty with the inferocentral pedicle. In: Hamdi M., Hammond D.C., Nahai F., editors. Vertical scar mammaplasty. Berlin: Springer, 2005. 